\title{
GEOSPATIAL ANALYSIS OF ENVIRONMENT POLLUTION
}

\author{
Medjon Hysenaj ${ }^{1}$ \\ 1 University of Shkoder, Sheshi 2 Prilli, Rruga Studenti 24, Shkoder, Albania, e-mail: mhysenaj@unishk.edu.al
}

Received: 2015.11.10

Accepted: 2015.12.09

Published: 2016.01.06

\begin{abstract}
The paper goal is to develop a spatial analyses of the most critical environmental issues in the country and how the population concerns could be addressed with the use of spatial technologies. Population perception of environment management relies on its minimum levels. In the recent past, static, fixed scale, multi use, highly accurate, permanent, paper maps compiled over a short period of time was the norm, meanwhile today's world uses a dynamic, single use, variable accuracy, variable scale, digital product made from data possibly retrieved from database derived from multiple sources. The opportunity to combine spatial technology associated with numerical data leading to a structured and genuine analyzes of the country issues turns to be an optimal strategy. We structure a set of digital maps encouraging decision-makers to rely their performance on spatial tools. Coastline pollution stands as a top priority. For the purpose of the analysis, the entire coastline was divided into sectors. Hence, further investigations could be addressed toward space-time relationship to cover the environmental evolution process, which may serve as an input for future predictions.
\end{abstract}

Keywords: coastline, geospatial analysis, environment pollution, spatial technology, digital map.

\section{INTRODUCTION}

Environmental issues, such as water and air pollution, waste management, deforestation, etc. affect population health and also cause significant economic damage. We must proceed with a constant monitor process which leads to healthy stimuli of the population towards current phenomena. The awareness of environmental issues stimulates people's perception regarding the surrounding environments [Douglas and Sasathorn, 2012]. Through spatial technologies we create a healthy strategy to manage the root anomalies surrounding a human. GIS technologies offer a better solution to understand spatial phenomenon and also give a clear picture of the periodical changes in time.

For air pollution several issues are indicated as primary factors, such as urbanization, old and amortized vehicles, uncontrolled factory process including inert management, chaotic constructions, etc. Air contamination in the country varies 2-3 times higher compared to other EU countries. Soil and water pollution claims factors such as urban discharges, sewage pipelines, irresponsible human activity, etc. The shoreline suffers from intense pollution where half of it is almost out of any allowed parameter, inert have turned already into a daily phenomenon, extended in major areas of the territory. As a result, the overall picture seems to be more than pessimistic. Geographic information system technology is used to support and deliver information to environmental managers and the public. GIS allows the combination and analysis of multiple layers of location-based data, including environmental measurements [Esri, 2010]. The paper aims to benefit from GIS utilities overlapping multiple layers reflecting different themes to highlight specific issues. We produce interesting results through the combination of environmental data versus spatial extension. Allocations such as:

- air pollution/population density;

- urban waste/ population distribution;

- fragmentation of the coastline, to rearrange our decision-making model improving our future management strategy. 


\section{EVALUATION STRATEGY}

We expose environment issues through spatial analysis. The country territory was categorized into regional level, acting as a support layer. Further, we overlay thematic layers related to the current issue.

The goal is to forehand population awareness by improving the communication process. According to Larsen, the monitoring process is a four step process (Figure 1). First, we gather data through a remote sensing process, generally satellites cover this phase best [Larsen, 2005]. Rough data must be processed for the purpose of consistency evaluation, also verified for reliability and updated information. As a final step, structured data must be ready to be analyzed by responsible authorities with the goal to improve decision performance and lead the management level into a more sustainable standard.

On the other hand, data should act as an informative source for most of the population. The goal of the paper is to present a set of digital maps basically covering the three most important environment concerns, such as water, air and soil management. Through the country territory we consider the regions with the largest area or the highest population density to express the outcome of air and waste measurements, compared to the European Union levels. As for water management we analyzed the most frequented coastline sectors.

Environmental management is inherently a spatial endeavor. Its data are particularly complex as they require two descriptors; namely, precise location of what is being described, as well as a clear description of its physical characteristics [Joseph, 1999]. The web GIS is an extension and application of client/server computing, where the geospatial data is accessible in a shareable environment [Harish et al, 2007]. Through geo-tools we aim to define statistically that part of population which is mostly exposed to any pollution level (air, water, soil, etc) based on a specific geograph- ic distribution. Through digital maps we set a new standard of environment evaluation which is more precise and objective. We aim to create a reasonable background for decision-making regarding the environmental problem [Pior et al, 1997].

\section{AIR POLLUTION}

The scenario from the first map overlays two layers where the country territory is categorized at district level with a scale map of $1: 2250000$. The first layer indicates population density where major districts have been taken into account as an input for further measurements in the second layer. LNP is one of the most important indicators related to the presence of dust particle $\left(\mathrm{mg} / \mathrm{m}^{3}\right)$ in the air. We notice that all major districts exceed the level defined by the EU by at least 2-3 times. We must take measures to improve life quality through short-term and long-term projects. Since long-term projects require strict limits of in place population movements, short-term projects could be more appropriate through strict preventing policy, also population awareness. We present the LNP indicator for air pollution through a comparative schema toward the European Union level (Figure 2).

\section{SOIL POLLUTION}

For the second case, we introduce a set of vector based areas derived from GADM (Global Administrative Areas). The geographic coordinate system is GCS_WGS_1984 and the datum D_WGS_1984. The map uses a 1:2.250.000 mapping scale. We offer the relation between waste generation and population deployment. Waste management is considered a problematic issue that requires improved operational performance in the future by the responsible authority. The digital map presents the urban waste diffusion

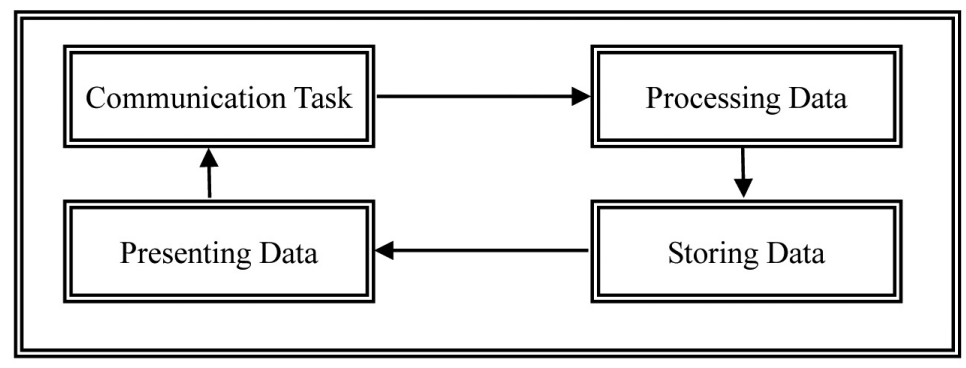

Figure 1. Monitor process of environment issues through GIS technology [Larsen 2005] 


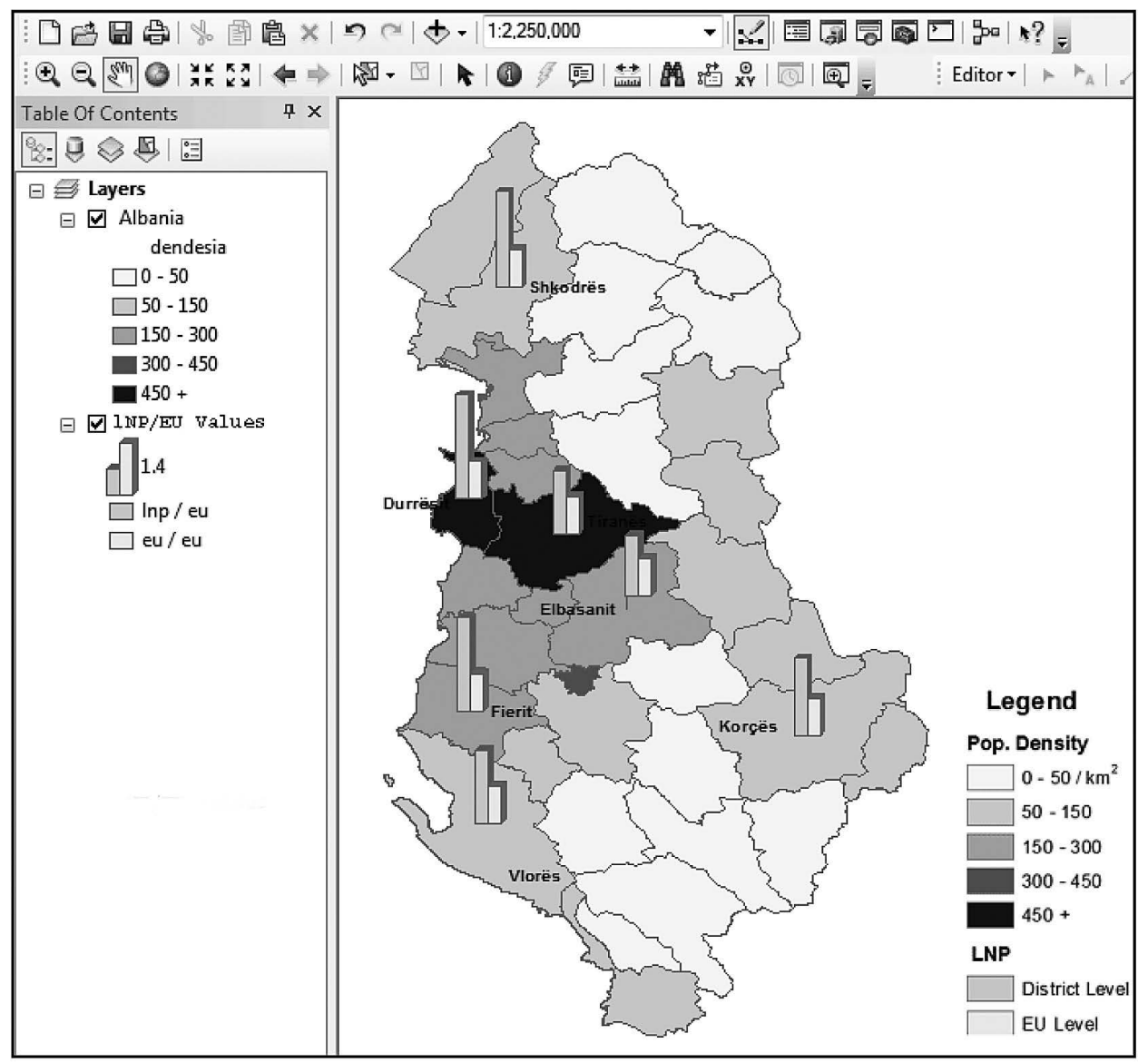

Figure 2. Measurement of air pollution, spatial extension - Region level (software: ArcMap 10)

[Ministry of Environment]

through a spatial distribution at regional level (Figure 3). The results are somewhat expected. The areas with minimum waste exploitation are those with a low number of population. Broadly, the higher the population distribution, the more obvious the critical issue of urban waste management.

\section{COASTLINE POLLUTION}

Many coastal ecosystems still remain adversely affected by current land-use practices and the ever-growing demand for coastal lands from urbanization. And unfortunately, the recent economic recession is expected to provide only temporary respite in the trend of coastal land take [Czerniak et al., 2011].

In both developed and developing countries, the coastal zone is likely to undergo the most profound change in the near future [Niya, 2013]. The two primary factors for coastline change remains natural process and human intervention. Natural factors remain great forces that are hard to manage, while human processes belong to the classi- fied category which can be controlled and well managed.

The third scenario (Figure 4) presents the country coastline divided into 6 major zones, according to the visiting frequency. Coliform bacteria have been used to evaluate the quality of water. Two other groups of bacteria that are present in feces are: fecal streptococci (FS) and Clostridium (FC) [12]. The analyzed data of FS-50 and FC-50 indicators for water pollution claim the fact that half of the Albanian shoreline suffers from severe water pollution, meanwhile, the other half need urgent intervention to become appropriate.

As we notice from the map 3 is the most infected area where most of the checkpoints go beyond the EU zone normative. Zone 5 is considered the cleanest area in the country also supported by frequency statistics. Every year we notice a great influx of visitors into zone 5 , which is not a solution; because it can put into question its natural pure sea quality in the future. Responsible authorities need to settle severe policy guides to normalize and create a more equitable distribution of visitors throughout the whole country coastline. Further, we fragment the country coast- 


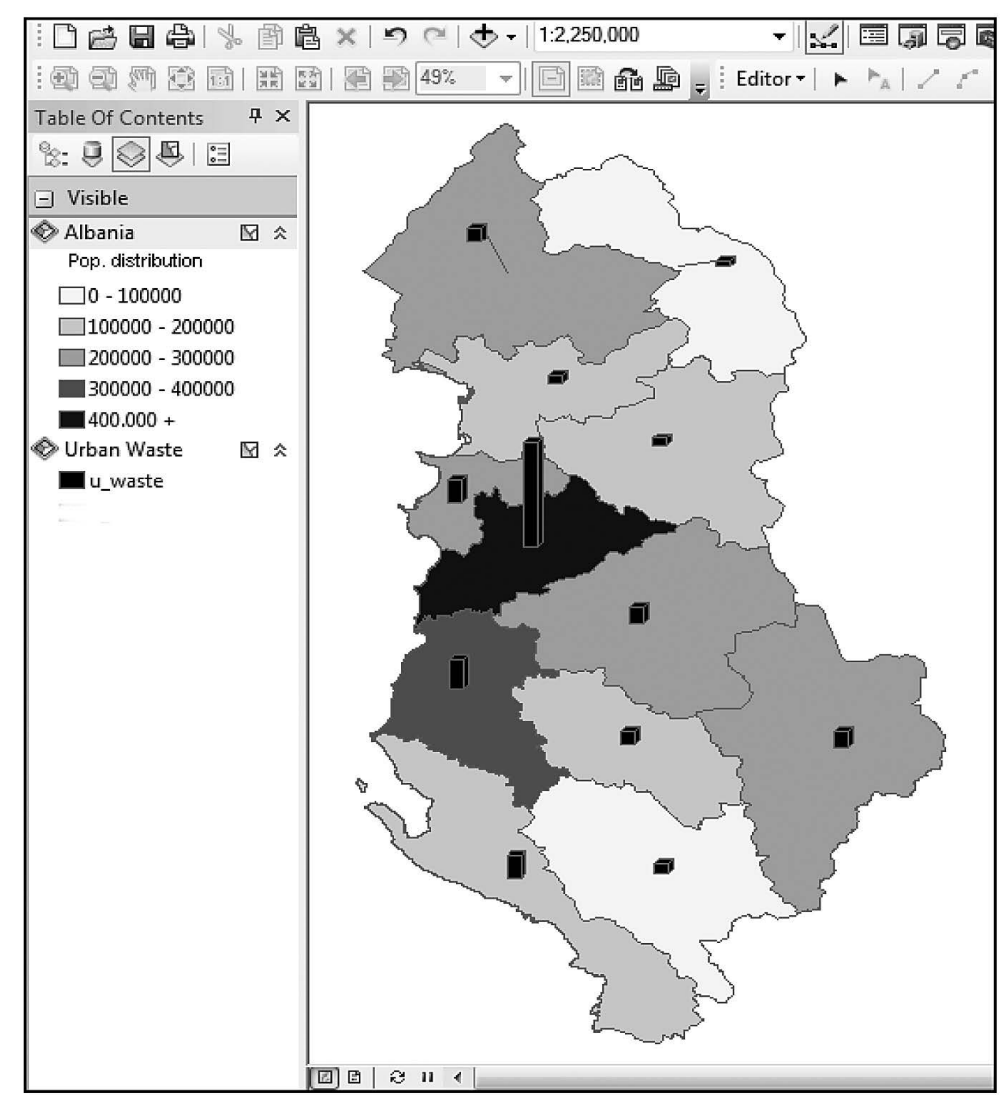

Figure 3. Measurement of urban waste, spatial extension - Region level (software: ArcMap 10) [Ministry of Environment]

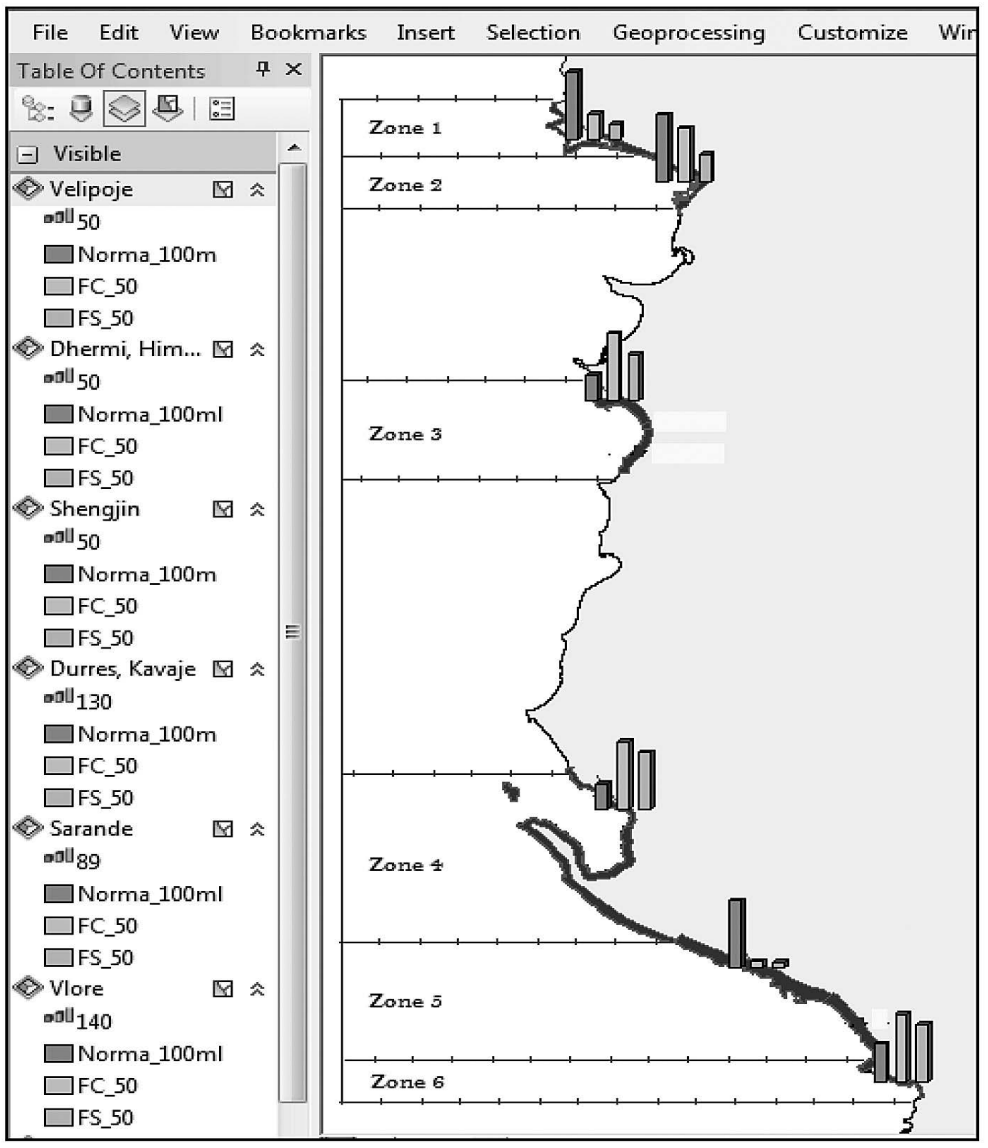

Figure 4. Measurement of coastline pollution, spatial extension - Region level (software: ArcMap 10) [Ministry of Environment] 
line to describe in detail the water coastline pollution and the associated check points.

\section{COASTLINE CHECKPOINT}

The study analyzes performed measures on 70 check point over the Albanian coastline. The goal is to define the most problematic areas concerning pollution values [MEFWA, 2014]. We obtain 36 problematic areas with high risk of bacteria, translated in other words half of the coastline is unsuitable to frequent. The primary reason that induces the verified situation is the uncontrolled urbanization phenomenon near these areas followed by unplanned investments, eager to benefit at the expense of coastal space leading to the degrada- tion of natural resources which will close development options. It is generally expected that Remote Sensing and GIS techniques and instruments will be of increasing importance in coastline and coastal zone management [Heuvel et al, 2009].

Through GIS technologies we intend to estimate the coastline situation creating a full picture overview of the current condition. This knowledge will enable coastal planners, inhabitants and decision makers to better understand and evaluate the current situation with the goal of improving the list of necessary steps to be undertaken.

Our investigation takes into consideration the values from Public Health Institute, which has set a limit of 100. Digital maps have been structured according to the coastline frequency and geographic

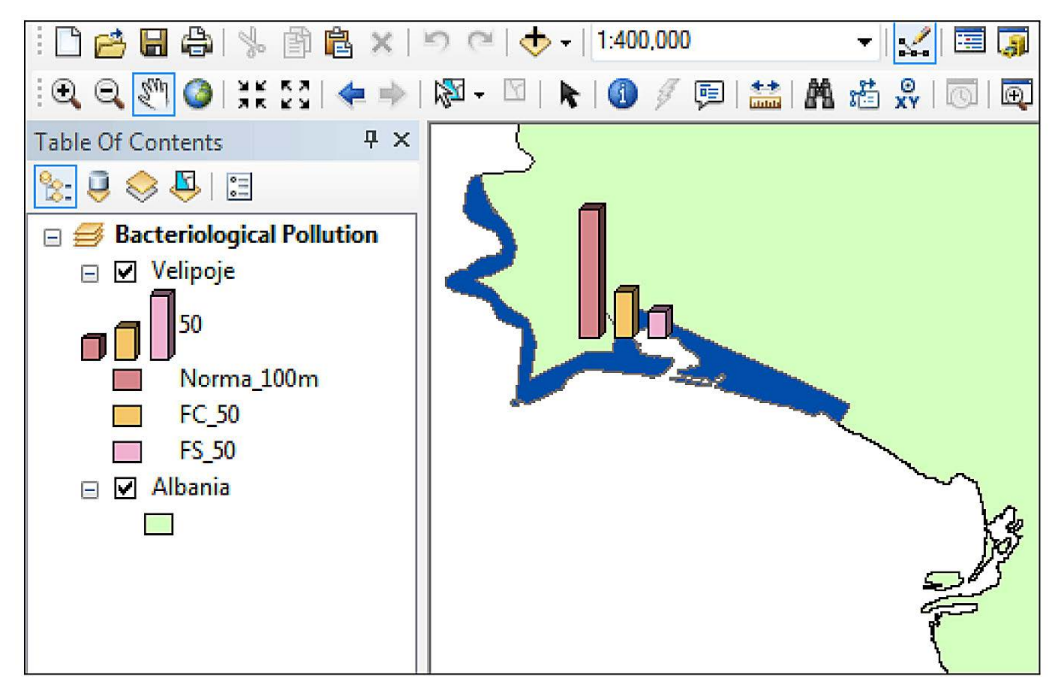

Table 1

\begin{tabular}{|c|c|c|}
\hline \multicolumn{3}{|c|}{ FC-50, FS-50 values } \\
\hline $\begin{array}{c}\text { Check } \\
\text { Point }\end{array}$ & FC-50 & FS-50 \\
\hline $\mathbf{1}$ & 40 & 23 \\
\hline $\mathbf{2}$ & 35 & 24 \\
\hline $\mathbf{3}$ & 33 & 20 \\
\hline $\mathbf{4}$ & 29 & 14 \\
\hline $\mathbf{5}$ & 48 & 27 \\
\hline $\mathbf{6}$ & 34 & 22 \\
\hline $\mathbf{7}$ & 33 & 20 \\
\hline Average & 36 & 21 \\
\hline $\begin{array}{l}\text { Norma } \\
\text { 100 } \mathbf{~ m l}\end{array}$ & 100 & 100 \\
\hline
\end{tabular}

Figure 5. Albania coastal pollution, study zone: Velipojë (software: Package ArcGIS, ArcMap 10) [Ministry of Environment, Forestry and Water Administration]

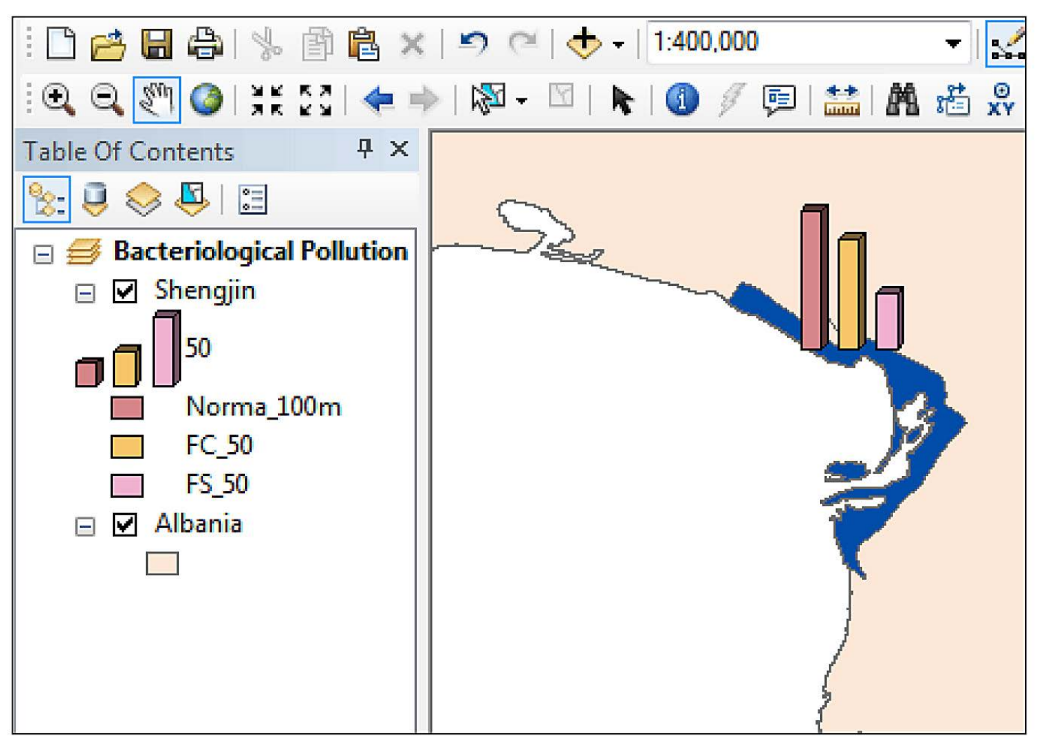

Table 2

\begin{tabular}{|c|c|c|}
\hline \multicolumn{3}{|c|}{ FC-50, FS-50 values } \\
\hline $\begin{array}{c}\text { Check } \\
\text { Point }\end{array}$ & FC-50 & FS-50 \\
\hline $\mathbf{8}$ & 85 & 45 \\
\hline $\mathbf{9}$ & 128 & 87 \\
\hline $\mathbf{1 0}$ & 56 & 20 \\
\hline $\mathbf{1 1}$ & 83 & 36 \\
\hline $\mathbf{1 2}$ & 46 & 19 \\
\hline Average & 80 & 41 \\
\hline $\begin{array}{l}\text { Norma } \\
\mathbf{1 0 0} \mathbf{~ m l}\end{array}$ & 100 & 100 \\
\hline
\end{tabular}

Figure 6. Albania coastal pollution, study zone: Shëngjin (software: Package ArcGIS, ArcMap 10) [Ministry of Environment, Forestry and Water Administration] 
location. Second hand beaches have been grouped for study reason. As source map we use a vector based map under the GCS_WGS_1984 projection will a scale of 1:400.000. We notice that (Figure $5,6)$ the northern coast covering two important beaches, Velipoja and Shëngjin, is considered an acceptable area to frequent. From the 12 measured check points only Shëngjin beach contain one critical area that exceeds the allowed limit (Table 1, 2).

If we move geographic down the territory (Figure 7) in the central zone of the Albanian coastline we face a serious situation. The generated values induce us in categorizing Durrës and many parts of Kavaja beach among the areas with the highest risk factor. As we clearly check from the map and the relevant table, most of the values not only exceed the defined normative but boost by multiple times the limit of 100 . All of the 21 check points that belong to Durrës beach are considered inappropriate to be visited (Table 3). As for Kavaja shoreline the situation seems to be more optimistic in half of the coast but still the other half needs urgent intervention (Table 4). According to these values, we can rank these important beaches as the most polluted areas in the whole Albanian coastline. Moving into the south the situation seems to improve. Many areas in Vlora beaches (figure 8) are adaptable with ac- ceptable parameters. Out of 11 measured check points, 7 seem to have good quality water (Table 5). Still, if we look carefully, there is especially one zone that exceeds the limit by 15 times and three more by 3 or 4 times.

Not by chance, Dhërmi, Himarë and Borsh (Figure 9) are the cleanest beaches. According to the map and the corresponding values the average of the measured parameters (Table 6), $\mathrm{FC}=9.8$ and $\mathrm{FS}=7.5$, ranks them among the most attractive areas by native and foreigners. They act as point of reference.

The southern beach of Saranda ends the country coastline. Based on the map (Figure 10) and the relevant table (Table 7) we conclude that the situation doesn't seem to improve joining the pessimistic overview created by the overall panorama of the whole country shoreline. Mapping the coastline situation is a mandatory input of vital importance for further decision-making progress [Hysenaj, 2011]. We insist on leading further digital mapping projects to investigate environmental issues for the benefit of population welfare. The application of GIS and remote sensing techniques to monitor coastline change should be carried out jointly with routine observatory work in order to improve our understanding of the environmental problematic [Tang, 2002].

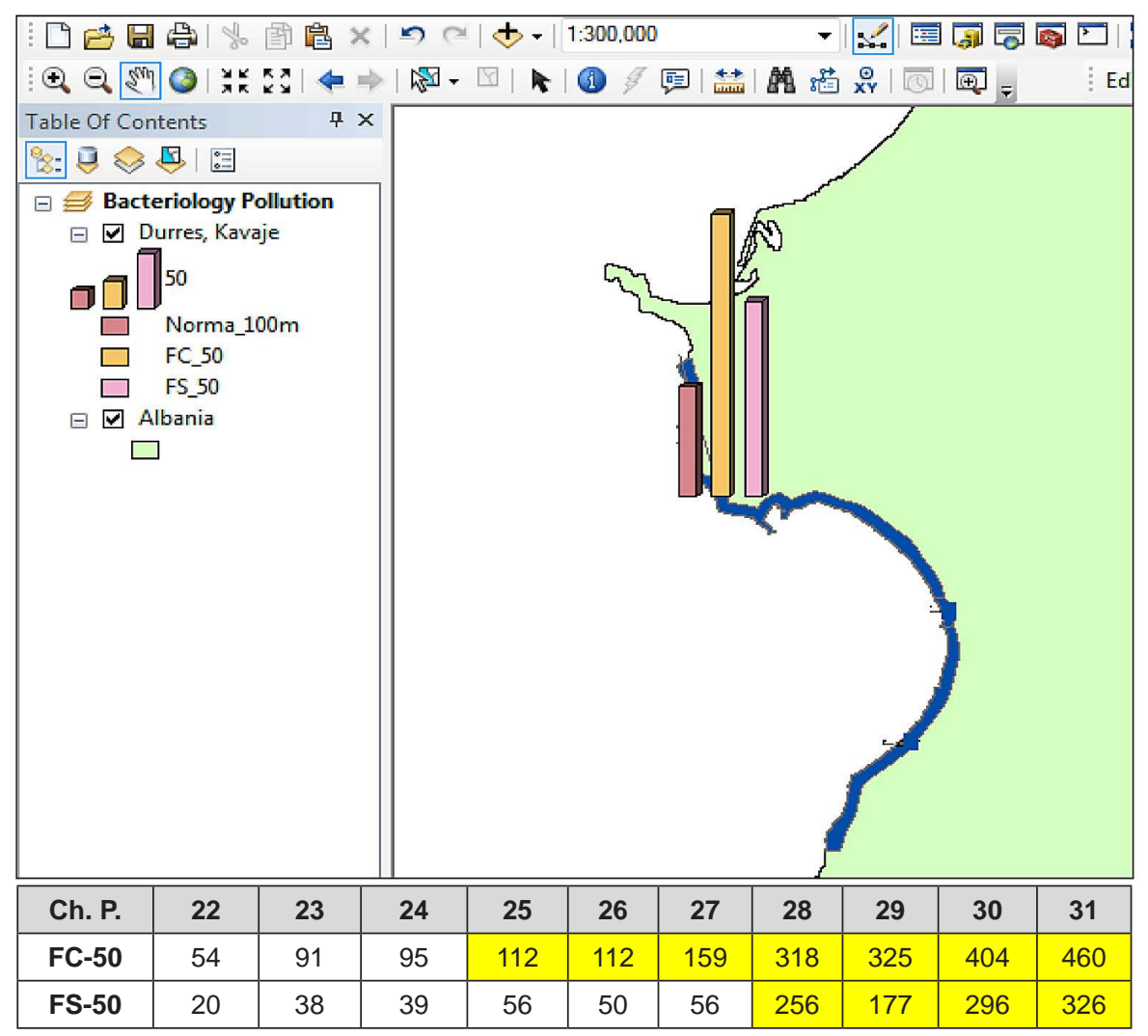

Table 3

\begin{tabular}{|c|c|c|}
\hline \multicolumn{3}{|c|}{ FC-50, FS-50 values } \\
\hline Ch. P. & FC-50 & FS-50 \\
\hline $\mathbf{1}$ & 1073 & 669 \\
\hline $\mathbf{2}$ & 906 & 687 \\
\hline $\mathbf{3}$ & 679 & 435 \\
\hline $\mathbf{4}$ & 640 & 591 \\
\hline $\mathbf{5}$ & 455 & 424 \\
\hline $\mathbf{6}$ & 281 & 206 \\
\hline $\mathbf{7}$ & 247 & 194 \\
\hline $\mathbf{8}$ & 199 & 161 \\
\hline $\mathbf{9}$ & 186 & 142 \\
\hline $\mathbf{1 0}$ & 171 & 135 \\
\hline $\mathbf{1 1}$ & 162 & 124 \\
\hline $\mathbf{1 2}$ & 162 & 107 \\
\hline $\mathbf{1 3}$ & 154 & 118 \\
\hline $\mathbf{1 4}$ & 151 & 104 \\
\hline $\mathbf{1 5}$ & 142 & 118 \\
\hline $\mathbf{1 6}$ & 140 & 93 \\
\hline $\mathbf{1 7}$ & 130 & 95 \\
\hline $\mathbf{1 8}$ & 121 & 92 \\
\hline $\mathbf{1 9}$ & 118 & 88 \\
\hline $\mathbf{2 0}$ & 115 & 72 \\
\hline $\mathbf{2 1}$ & 114 & 81 \\
\hline Average & 271 & 226 \\
\hline Norma & $\mathbf{1 0 0}$ & $\mathbf{1 0 0}$ \\
\hline $\mathbf{1 0 0} \mathbf{m l}$ & \multicolumn{2}{|c}{} \\
\hline
\end{tabular}

Figure 7. Albania coastal pollution, study zone: Durrës, Kavajë 


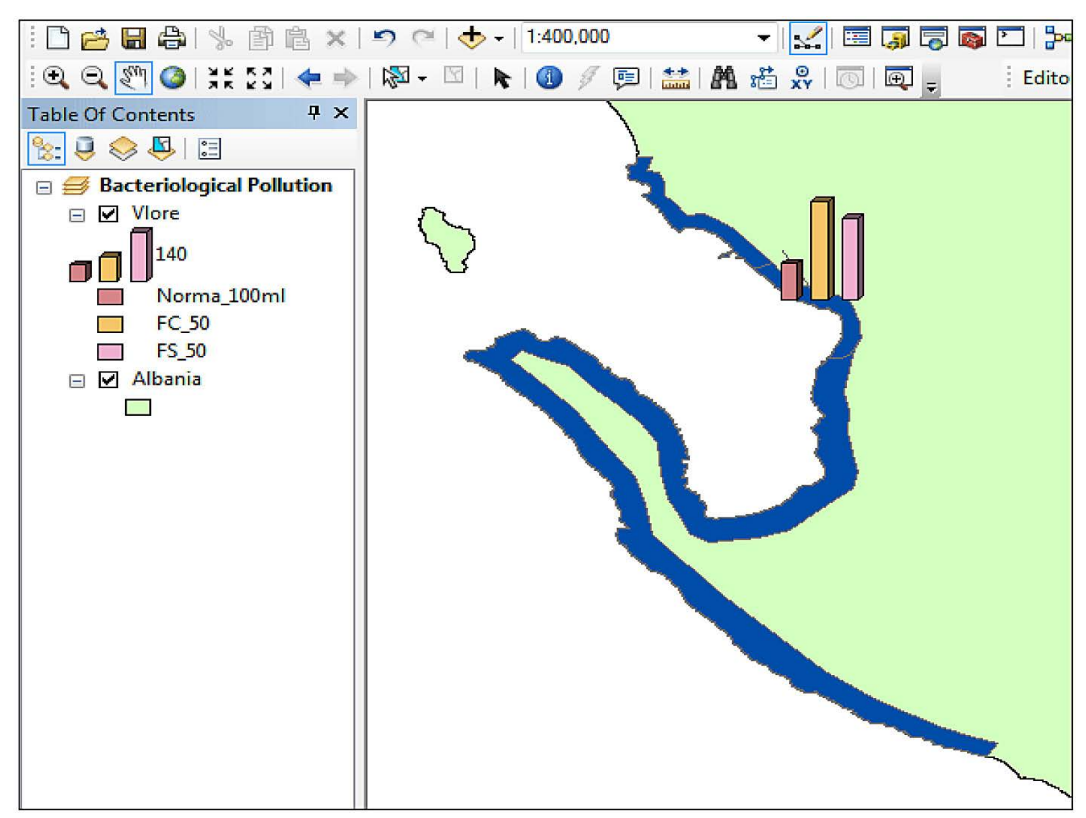

Table 4

\begin{tabular}{|c|c|c|}
\hline \multicolumn{3}{|c|}{ FC-50, FS-50 values } \\
\hline $\begin{array}{c}\text { Check } \\
\text { Point }\end{array}$ & FC-50 & FS-50 \\
\hline $\mathbf{1}$ & 355 & 317 \\
\hline $\mathbf{2}$ & 437 & 318 \\
\hline $\mathbf{3}$ & 1519 & 1304 \\
\hline $\mathbf{4}$ & 466 & 429 \\
\hline $\mathbf{5}$ & 41 & 23 \\
\hline $\mathbf{6}$ & 33 & 23 \\
\hline $\mathbf{7}$ & 28 & 16 \\
\hline $\mathbf{8}$ & 23 & 12 \\
\hline $\mathbf{9}$ & 24 & 14 \\
\hline $\mathbf{1 0}$ & 38 & 19 \\
\hline $\mathbf{1 1}$ & 23 & 14 \\
\hline Average & 271 & 226 \\
\hline $\begin{array}{c}\text { Norma } \\
\mathbf{1 0 0} \mathbf{~ m l}\end{array}$ & $\mathbf{1 0 0}$ & $\mathbf{1 0 0}$ \\
\hline \multicolumn{2}{|c}{} \\
\hline
\end{tabular}

Figure 8. Study zone: Vlorë

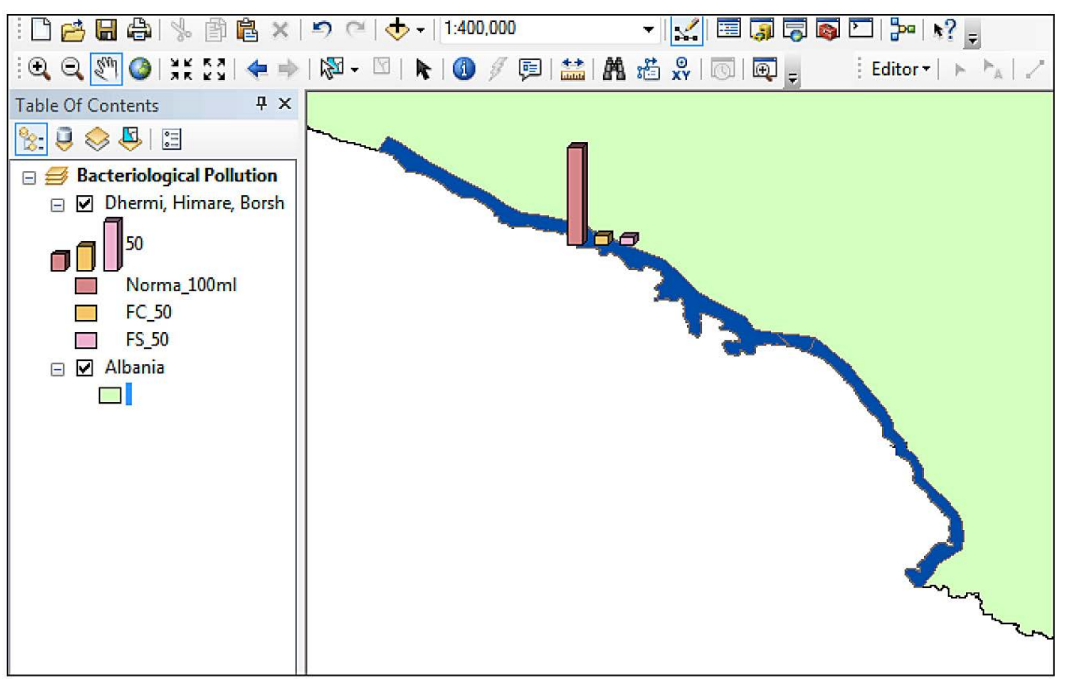

Table 5

\begin{tabular}{|c|c|c|}
\hline \multicolumn{3}{|c|}{ FC-50, FS-50 values } \\
\hline $\begin{array}{c}\text { Check } \\
\text { Point }\end{array}$ & FC-50 & FS-50 \\
\hline $\mathbf{1}$ & 9.1 & 6.5 \\
\hline $\mathbf{2}$ & 11 & 7.1 \\
\hline $\mathbf{3}$ & 12.3 & 9.5 \\
\hline $\mathbf{4}$ & 13 & 18 \\
\hline $\mathbf{5}$ & 8 & 6 \\
\hline $\mathbf{6}$ & 5 & 3 \\
\hline $\mathbf{7}$ & 9 & 7 \\
\hline $\mathbf{8}$ & 8 & 5 \\
\hline $\mathbf{9}$ & 11 & 7 \\
\hline $\mathbf{1 0}$ & 12 & 7 \\
\hline Average & 9.8 & 7.5 \\
\hline $\begin{array}{c}\text { Norma } \\
\mathbf{1 0 0} \text { ml }\end{array}$ & $\mathbf{1 0 0}$ & $\mathbf{1 0 0}$ \\
\hline
\end{tabular}

Figure 9. Study zone: Dhërmi, Himarë, Borsh

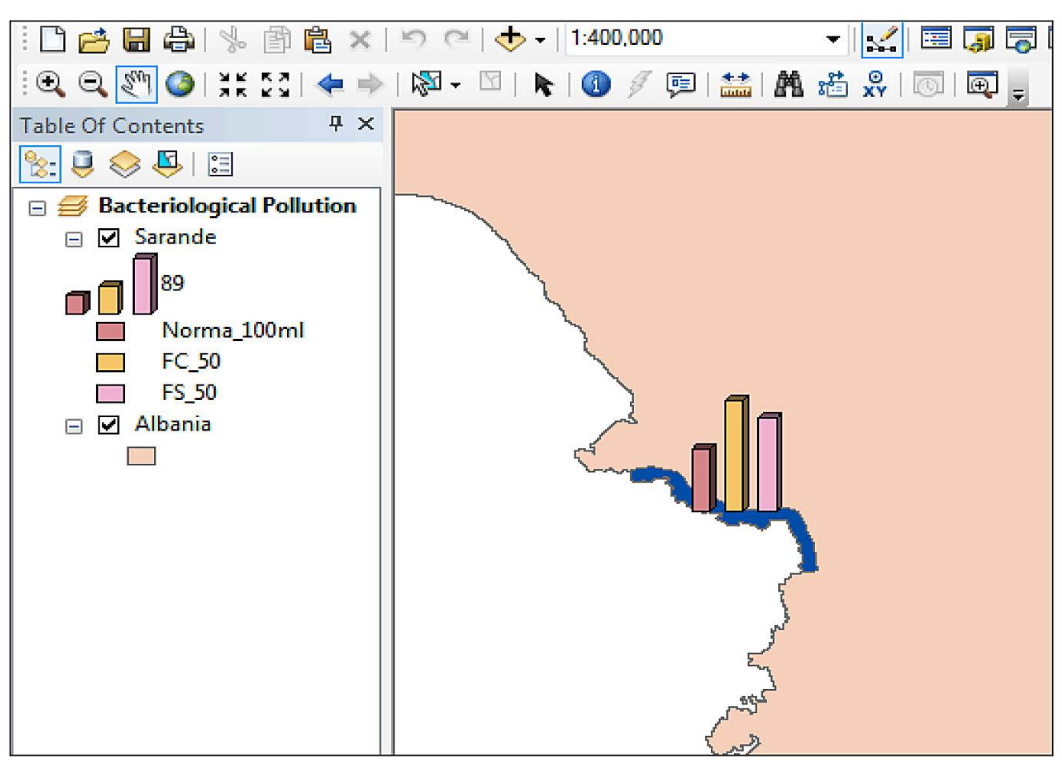

Table 6

\begin{tabular}{|c|c|c|}
\hline \multicolumn{3}{|c|}{ FC-50, FS-50 values } \\
\hline $\begin{array}{c}\text { Check } \\
\text { Point }\end{array}$ & FC-50 & FS-50 \\
\hline $\mathbf{1}$ & 29 & 16 \\
\hline $\mathbf{2}$ & 30 & 19 \\
\hline $\mathbf{3}$ & 124 & 103 \\
\hline $\mathbf{4}$ & 146 & 121 \\
\hline $\mathbf{5}$ & 69 & 58 \\
\hline $\mathbf{6}$ & 670 & 580 \\
\hline Average & 178 & 150 \\
\hline $\begin{array}{c}\text { Norma } \\
\mathbf{1 0 0} \text { ml }\end{array}$ & $\mathbf{1 0 0}$ & $\mathbf{1 0 0}$ \\
\hline
\end{tabular}

Figure 10. Study zone: Sarandë 
The overall picture reveals that the measured indicators exceed quite often the normative values settled by the EU. The maps are particularly useful due to their performance to combine spatial extension with statistical data. Multiple layer overlay improves the endeavor to manage environmental pollution for the developed analysis.

\section{CONCLUSIONS}

GIS technology manages statistical and spatial data to provide a tool that shows the relationship between critical issues and occurrences of deficient human and environmental health [Esri, 2007]. The results in the paper induce us to improve the monitor process followed by a constant informative platform. Through spatial tools we create digital maps targeting population awareness. Due to a tearing urbanization process, $\mathrm{Al}$ bania must face sharp problematic related to environment pollution (air, water, soil, etc) which need to be monitored. Still we focus on the coastline issue in Albania which remains priority due to its particular importance in the economic and management sector. Through remote sensing, we easily gain access to spatial data which used into the proper software can produce important outcome for the benefit of coastline planners and decision-makers.

We induce to use digital mapping as the right solution for issues that are spatially connected. Analyzing data from a visual perspective turns to be more productive than just rough data. We conclude that half of the coastline suffers from high level of pollution which makes them inappropriate to use. The other half still need correction in many areas. If some of them are still under pollution limits, it does not come because of their careful management, but simply because of nonmassive frequentation [ODA, 2011].

Through GIS technologies, environmental monitoring is created to estimate short and long term changes, to carry out risk assessment analysis and to develop models for prediction and optimization [Matejicek et al, 2003]. By exploiting GIS opportunity to overlay multiple thematic layers to combine geographical dispersion presentation with the environmental issues can produce interesting outcomes. The analyses in this paper aims to identify weak areas and key factors that induce the gradual degradation. The methods exploit the spatio-statistic relation for current analyses, also encourage for further investigations through spatial-time relationship. An environment process will be fully analysed when we combine current analysis carrying the complete knowledge background of its evolution process. By so we can improve our current and future policy.

\section{REFERENCES}

1. Czerniak P., Pickaver A., Ferreira M., Steijn R., Devilee E. 2011. Integrated Coastal Zone management information and technology in ICZM practices around Europe.

2. Douglas L., Sasathorn T. 2012. GIS for environmental problem solving. Department of Ecosystem Science and Management, Texas A\&M University, USA.

3. ESRI Corporate 2010. GIS solutions for environmental Management.

4. ESRI 2007. GIS for air quality.

5. Harish K., Sameer S., Karamjit B. 2007. Multicriteria spatial decision analysis in Web GIS environment. GeoInformatica.

6. Heuvel T., Roeland H. 2009. Coastline management with GIS in the Netherlands. National Institute for Coastal and Marine Management/RIKZ.

7. Hysenaj M. 2011 Geographical Information Systems.

8. Joseph K. 1999. GIS technology in environmental management: A brief history. Trends and Probable Future.

9. Larsen L. 2005. GIS in environmental monitoring and assessment.

10. Matejicek L., Benesova L., Tonika J. 2003. Mapping of environmental pollution in urban areas with GIS. Institute for Environmental Studies, Charles University in Prague, Czech Republic.

11. Ministry of Environment, Forestry and Water Administration. Source data for digital maps, 2014.

12. Niya A. 2013. Shoreline change mapping using remote sensing and GIS. International Journal of Remote Sensing Applications, 3(3).

13. Open Data Albania 2011. Quality of beaches, fecal coliforms and intestinal enterococcus indicators.

14. Pior M., Osman O. 1997. Air pollution assessment applying Geographical Integrated System. Journal of the Eastem Asia Society for Transportation Studies, 2(6).

15. Tang Y. 2002. The application of GIS and RS for coastline change detection and risk assesment to enhanced sea level rise. ITC.

16. Xiaopeng L., Bruce A. 2010. Running both analytical and digital photogrammetric production lines in mapping environment. ISPRS. 